\title{
Gordonia soli sp. nov., a novel actinomycete isolated from soil
}

\author{
Fo-Ting Shen, ${ }^{1}$ Michael Goodfellow, ${ }^{2}$ Amanda L. Jones, ${ }^{2}$ Ye-Pei Chen, ${ }^{1}$ \\ A. B. Arun, ${ }^{1}$ Wei-An Lai, ${ }^{1}$ P. D. Rekha ${ }^{1}$ and Chiu-Chung Young $^{1}$ \\ ${ }^{1}$ College of Agriculture and Natural Resources, Department of Soil and Environmental \\ Sciences, National Chung Hsing University, Taichung, 402, Taiwan, Republic of China \\ ${ }^{2}$ Division of Biology, King George VIth Building, University of Newcastle, Newcastle upon Tyne \\ NE1 7RU, UK
}

Correspondence

Chiu-Chung Young

ccyoung@mail.nchu.edu.tw
The genus Gordonia belongs to the family Gordoniaceae, a member of the suborder Corynebacterineae proposed by Stackebrandt et al. (1997). The taxon is well-defined and can be distinguished readily from the nine other genera that constitute the suborder, notably by using chemotaxonomic, morphological and 16S rRNA gene sequence data (Soddell et al., 2006a). At the time of writing the genus comprises 20 recognized species, most of which have been described in the last 10 years using polyphasic taxonomic approaches (Kim et al., 1999; Iida et al., 2005). All but one of these taxa have been isolated from natural and artificial habitats, including activated sludge foam (Soddell et al., 2006b), industrial wastewater (Kim et al., 2003), mangrove rhizosphere (Takeuchi \& Hatano, 1998), tar-contaminated soil (Kummer et al., 1999) and an oil-producing well (Xue et al., 2003). The exception, Gordonia otitidis Iida et al. 2005, belongs to the growing number of Gordonia species associated with human and animal diseases (Goodfellow \& Maldonado, 2006). However, in general, Gordonia strains are widely distributed in soil and aquatic habitats, including marine sediments (Goodfellow \& Maldonado, 2006).

The aim of the present study was to determine the taxonomic position of an actinomycete, designated strain $\mathrm{CC}-\mathrm{AB} 07^{\mathrm{T}}$, that formed a pale orange colony on a trypticase soy agar (TSA) plate that had been incubated at $30^{\circ} \mathrm{C}$ for

The GenBank/EMBL/DDBJ accession number for the 16S rRNA gene sequence of Gordonia soli CC-AB07 ${ }^{\top}$ is AY995560.
3 days following inoculation with a suspension of a soil sample collected from the campus of National Chung Hsing University, Taichung, Taiwan. The organism was subjected to a polyphasic taxonomic study, which showed that it was a novel species of the genus Gordonia.

Extraction of genomic DNA, PCR amplification and sequencing of 16S rRNA genes was carried out as described by Shen et al. (2005). Sequence analysis was performed using a DNA sequencer (ABI PRISM 310; Applied Biosystems) and sequence assembly by using the Fragment Assembly System program from the Wisconsin Package 9.1 supplied by the National Health Research Institute of Taiwan. The resultant sequence was compared with corresponding results taken from the RDP II database for representatives of the genera classified in the suborder Corynebacterineae. Phylogenetic trees were inferred using the maximumlikelihood, maximum-parsimony and neighbour-joining algorithms, as explained by Soddell et al. (2006a). The unrooted tree topologies were evaluated by bootstrap analyses (Felsenstein, 1985) of the neighbour-joining dataset using the SEQBOOT and CONSENSE options from the PHYLIP package (Felsenstein, 1989). A nearly complete 16S rRNA gene sequence (1485 nt) that corresponded to Escherichia coli positions 26-1511 (Brosius et al., 1978) was obtained for strain $\mathrm{CC}-\mathrm{AB} 07^{\mathrm{T}}$. A comparison of the sequence with those of representatives of the genera classified in the suborder Corynebacterineae showed that the organism fell within the evolutionary radiation occupied by the genus Gordonia 


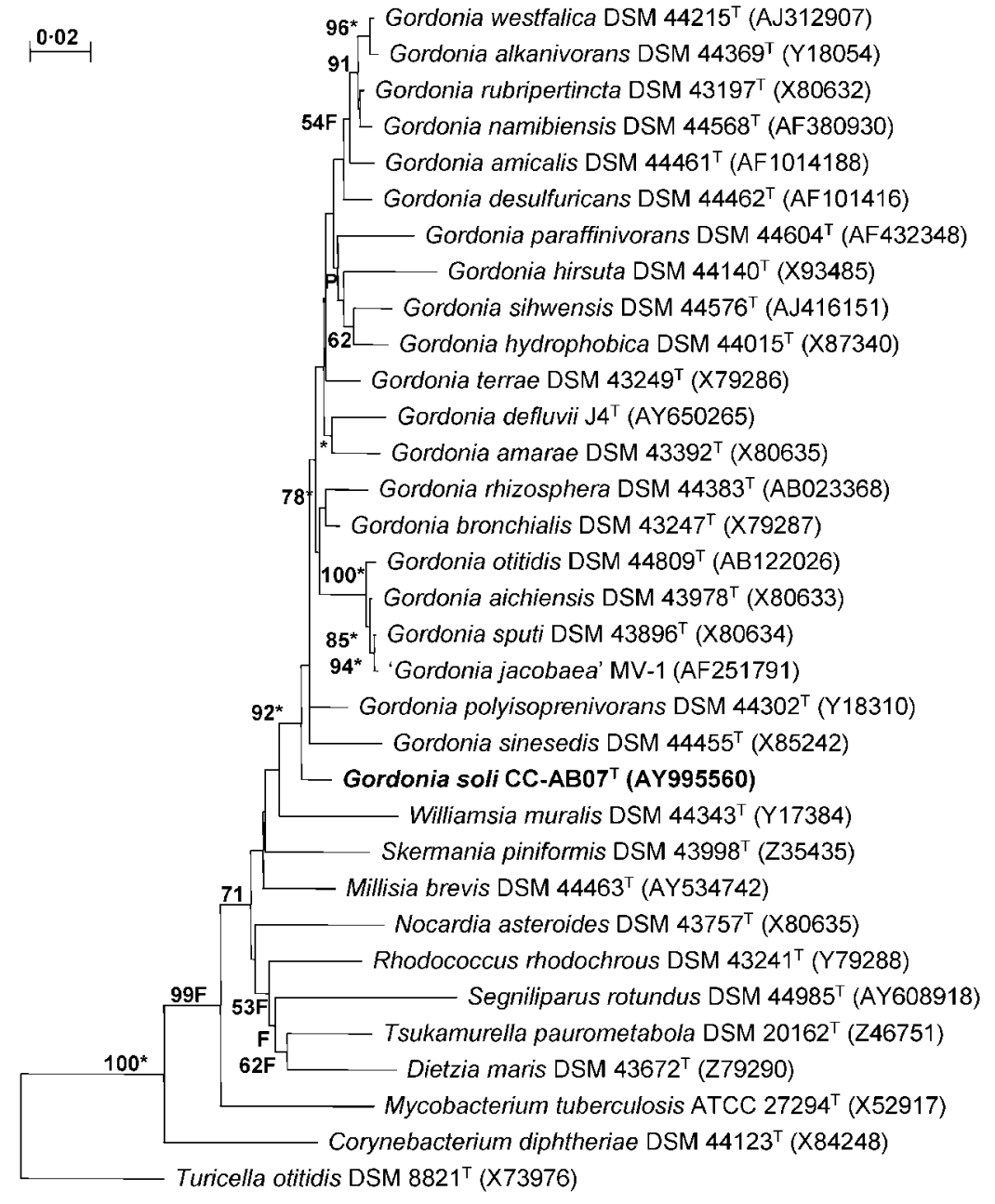

Fig. 1. Neighbour-joining tree (Saitou \& Nei, 1987) based on nearly complete $16 \mathrm{~S}$ rRNA gene sequences showing the position of strain $\mathrm{CC}-\mathrm{ABO} 7^{\top}$ within the radiation occupied by the genus Gordonia. Asterisks indicate branches of the tree that were also recovered using the maximum-likelihood (Felsenstein, 1981) and maximum-parsimony (Fitch, 1971) algorithms. $F$ and $P$ indicate branches that were also recovered using the least-squares and maximum-parsimony methods, respectively. Numbers at the nodes are percentage bootstrap values based on 1000 resampled datasets; only values above $50 \%$ are given. Bar, 0.02 substitutions per nucleotide position. (data not shown). 16S rRNA gene sequence similarity between strain $\mathrm{CC}-\mathrm{AB} 07^{\mathrm{T}}$ and the type strains of members of the genus Gordonia ranged from $94 \cdot 0$ to $98 \cdot 2 \%$.

Chemosystematic studies were carried out to establish whether strain $\mathrm{CC}-\mathrm{AB} 07^{\mathrm{T}}$ had a chemical profile consistent with its assignment to the genus Gordonia. Biomass for chemical studies was grown in shake flasks of glucose-yeast extract broth (Gordon \& Mihm, 1962) for 5 days at $28{ }^{\circ} \mathrm{C}$, checked for purity, harvested by centrifugation, washed twice in distilled water and freeze-dried. Standard methods were used for analysis of the isomers of diaminopimelic acid, fatty acids, isoprenoid quinones, muramic acid type, mycolic acids, polar lipids and sugars, as described by Soddell et al. (2006b). The isolate contained mesodiaminopimelic acid, arabinose and galactose (wall chemotype IV sensu Lechevalier \& Lechevalier, 1970); N-glycolated muramic acid; dihydrogenated menaquinones with nine isoprene units as the predominant isoprenologue; phosphatidylethanolamine, diphosphatidylglycerol, phosphatidylglycerol, phosphatidylinositol and phosphatidylinositol mannosides as major polar lipids (phospholipid type II sensu Lechevalier et al., 1977) and a fatty acid profile rich in palmitic $\left(\mathrm{C}_{16: 0} ; 33.6 \%\right.$ of the total fatty acid composition), palmitoleic $\left(\mathrm{C}_{16: 1} ; 10 \cdot 4 \%\right)$, oleic $\left(\mathrm{C}_{18: 1} ; 11 \cdot 7 \%\right)$ and tuberculostearic $(29 \cdot 4 \%)$ acids. It was also characterized by the presence of mycolic acids that co-migrated $\left(R_{\mathrm{F}}\right.$ value $0 \cdot 47$ ) with those extracted from Gordonia bronchialis DSM $43247^{\mathrm{T}}$. All of these properties are typical of representatives of the genus Gordonia (Goodfellow \& Maldonado, 2006).

It is evident from the phylogenetic tree in Fig. 1 that strain $\mathrm{CC}-\mathrm{AB} 07^{\mathrm{T}}$ forms a monophyletic branch at the periphery of the evolutionary radiation occupied by the genus Gordonia. The organism was most closely related to G. bronchialis DSM $43247^{\mathrm{T}}$, sharing a $16 \mathrm{~S}$ rRNA gene sequence similarity of $98 \cdot 2 \%$, a value that corresponds to $26 \mathrm{nt}$ differences at 1468 locations. Strain $\mathrm{CC}-\mathrm{AB} 07^{\mathrm{T}}$ also shares comparatively high $16 \mathrm{~S}$ rRNA gene sequence similarities with the type strains of Gordonia polyisoprenivorans (98.1\%), Gordonia rhizosphera (97.7\%), Gordonia amicalis (97.6\%), Gordonia desulfuricans $(97 \cdot 6 \%)$, Gordonia terrae (97.4\%), Gordonia westfalica (97.4\%), Gordonia alkanivorans $(97 \cdot 3 \%)$ and Gordonia rubripertincta (97-3\%). DNADNA relatedness experiments were not carried out between strain $\mathrm{CC}-\mathrm{AB} 07^{\mathrm{T}}$ and its closest phylogenetic neighbours as the type strains of several Gordonia species share higher 16S rRNA gene sequence similarities, but have levels of 


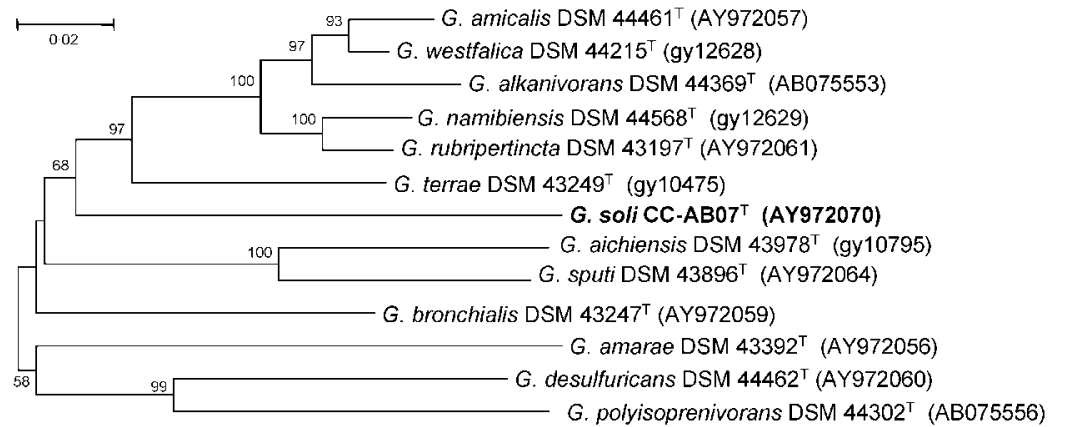

Fig. 2. Neighbour-joining analysis based on gyrB nucleotide sequences showing the position of strain $\mathrm{CC}-\mathrm{AB} 07^{\top}$ within the radiation occupied by the genus Gordonia. Numbers at the nodes are percentage bootstrap values based on 1000 resampled datasets; only values above $50 \%$ are given. The gyrB gene sequences of the type strains of members of the genus Gordonia were retrieved from the EMBL and ICB (http://seasquirt.inbio.co.jp/icb/) databases. Bar, 0.02 substitution $\left(K_{\text {nuc }}\right)$ units.
DNA-DNA relatedness well below the $70 \%$ cut-off point recommended for the assignment of strains to the same genomic species (Wayne et al., 1987). The type strains of $G$. alkanivorans and G. rubripertincta, for example, have a $16 \mathrm{~S}$ rRNA gene sequence similarity of $99 \cdot 1 \%$ (which corresponds to a 13-nt difference), but a DNA-DNA relatedness value of only $52 \%$ (Kummer et al., 1999).

The gyrB nucleotide sequence of strain $\mathrm{CC}-\mathrm{AB} 07^{\mathrm{T}}$ was determined following the procedures described by Shen et al. (2006). Degenerate PCR primers GYRB1 and GYRB2 were designed and used to amplify a $g y r B$ fragment of approximately $1 \cdot 2 \mathrm{~kb}$ from the genomic DNA extracted from the type strains of recognized Gordonia species. Sequencing primers were designed from the flanking regions of $g y r B$ conserved sequences with two forward primers, GYRBF1 and GYRBF2, and the reverse primer GYRBR1. The resultant sequence was compared with corresponding gyrB sequences of available Gordonia type strains drawn from the EMBL and ICB database (http://seasquirt.mbio. co.jp/icb/) using the CLUSTAL_X program (Thompson et al., 1997). A phylogenetic tree was inferred with the neighbourjoining algorithm (Saitou \& Nei, 1987) using MEGA version 2.1 software (Kumar et al., 2001). An evolutionary distance matrix was generated as described by Kimura (1980). The resultant unrooted tree was evaluated by bootstrap analysis (Felsenstein, 1985) of the neighbour-joining method based on 1000 resamplings.

It can be seen from Fig. 2 that strain $\mathrm{CC}-\mathrm{AB} 07^{\mathrm{T}}$ forms a distinct phyletic line in the Gordonia gyrB gene sequence tree. The strain is most closely related to G. amicalis DSM $44461^{\mathrm{T}}(84 \cdot 5 \%$ gyrB gene sequence similarity), G. desulfuricans $(81 \cdot 3 \%)$, G. polyisoprenivorans $(79 \cdot 8 \%)$, G. rhizosphera DSM $44383^{\mathrm{T}}(78 \cdot 8 \%)$, Gordonia sputi DSM $43896^{\mathrm{T}}$ (78.0 \%), G. bronchialis DSM $43247^{\mathrm{T}}(77 \cdot 9 \%)$ and Gordonia aichiensis DSM $43978^{\mathrm{T}}(77 \cdot 5 \%)$. These data provide further evidence that isolate $\mathrm{CC}-\mathrm{AB} 07^{\mathrm{T}}$ is not particularly closely related to representatives of recognized Gordonia species, especially as classifications based on gyrB gene nucleotide sequence data correlate well with those based on corresponding DNA-DNA relatedness data (Shen et al., 2006). These workers determined gyrB gene sequence similarities between the type strains of 12 recognized Gordonia species and reported similarity values in the range $79 \cdot 3-97 \cdot 2 \%$
(41-270 nt difference); the corresponding 16S rRNA gene sequences differed within the range $0 \cdot 3-3 \cdot 8 \%$.

Strain $\mathrm{CC}-\mathrm{AB} 07^{\mathrm{T}}$ was examined for a broad range of phenotypic properties, notably for features known to be of value in Gordonia systematics (Kim et al., 1999; Soddell et al., 2006b). Cultural characteristics were examined on a TSA plate that had been incubated for 2 days at $30{ }^{\circ} \mathrm{C}$. Smears taken from the plate were Gram-stained (Shen et al., 2005) and examined for micromorphological properties. Additional smears were stained using a modification of the Ziehl-Neelsen method (Gordon, 1967) to determine whether the organism was acid-alcohol-fast. Standard biochemical and degradation tests were carried out using well-established procedures (Kim et al., 1999). The enzymic profile of strain $\mathrm{CC}-\mathrm{AB} 07^{\mathrm{T}}$ was determined using API Coryne (bioMérieux) and API ZYM (bioMérieux) kits according to the manufacturer's instructions. Similarly, sole carbon source tests were performed using a Biolog GP-II kit. The ability of the organism to grow at a range of temperatures was determined on TSA plates and motility was tested as described by Shen et al. (2005). Oxidase activity was determined using oxidase reagent (bioMérieux). It is apparent from the results (Table 1) that strain $\mathrm{CC}-\mathrm{AB} 07^{\mathrm{T}}$ can be distinguished from representatives of its close phylogenetic relatives using a combination of phenotypic attributes.

It is clear from the genotypic and phenotypic data that strain $\mathrm{CC}-\mathrm{AB} 07^{\mathrm{T}}$ represents a novel species in the genus Gordonia. The name Gordonia soli sp. nov. is proposed for this taxon.

\section{Description of Gordonia soli sp. nov.}

Gordonia soli (so.li. L. gen. n. soli of/from the soil).

Aerobic, Gram-positive, partially acid-alcohol-fast, nonmotile actinomycete that forms elementary branching hyphae that fragment into rods and cocci. Pale orangecoloured, circular colonies (about $2 \mathrm{~mm}$ in diameter) with filamentous margins are formed on TSA after incubation for 2 days at $30{ }^{\circ} \mathrm{C}$. Neither aerial hyphae nor diffusible pigments are produced. Grows at $\mathrm{pH} 5 \cdot 5-10 \cdot 0$ and at $28-35^{\circ} \mathrm{C}$, but not at 4 or $40^{\circ} \mathrm{C}$. Degrades starch, produces catalase and oxidase, but does not hydrolyse allantoin or arbutin. Acid and alkaline phosphatase, butyrate esterase, 
Table 1. Phenotypic characteristics that differentiate strain $\mathrm{CC}-\mathrm{AB} 07^{\top}$ from representatives of closely related Gordonia species

Taxa: 1, CC-AB07 $7^{\mathrm{T}}$; 2, G. alkanivorans DSM 44369 ; 3, G. amicalis DSM 44461 ${ }^{\mathrm{T}}$; 4, G. bronchialis DSM 43247 ${ }^{\mathrm{T}}$; 5, G. desulfuricans DSM $43247^{\mathrm{T}}$; 6, G. polyisoprenivorans DSM 44302 ${ }^{\mathrm{T}}$; 7, G. rhizosphera NBRC $16068^{\mathrm{T}}$; 8, G. rubripertincta DSM 43197 $7^{\mathrm{T}}$; 9 , G. terrae DSM 43249 ${ }^{\mathrm{T}}$; 10, G. westfalica DSM 44215. +, Positive; -, negative. Most of the data for the Gordonia type strains were taken from Maldonado et al. (2003); all of the results for the G. westfalica strain were determined in the present study, as were the API ZYM results for the type strains of G. polyisoprenivorans and G. rhizosphera. In the API ZYM tests, all of the strains produced acid phosphatase and $\alpha$-glucosidase.

\begin{tabular}{|c|c|c|c|c|c|c|c|c|c|c|}
\hline Characteristic & 1 & 2 & 3 & 4 & 5 & 6 & 7 & 8 & 9 & 10 \\
\hline Colony colour & $\begin{array}{c}\text { Pale } \\
\text { orange }\end{array}$ & $\begin{array}{c}\text { Pale } \\
\text { orange }\end{array}$ & Red & Brown & Pink & Orange & $\begin{array}{c}\text { Orange/ } \\
\text { red }\end{array}$ & $\begin{array}{l}\text { Pink/ } \\
\text { orange }\end{array}$ & $\begin{array}{l}\text { Pink/ } \\
\text { orange }\end{array}$ & $\begin{array}{l}\text { Pastel } \\
\text { orange }\end{array}$ \\
\hline \multicolumn{11}{|l|}{ API ZYM tests: } \\
\hline Alkaline phosphatase & + & - & - & + & + & + & - & - & - & - \\
\hline Butyrate esterase & + & + & + & + & + & + & - & + & + & + \\
\hline Caprylate esterase & + & + & + & - & + & + & + & + & + & + \\
\hline Cystine arylamidase & - & + & - & - & - & + & - & - & - & - \\
\hline$\beta$-Glucosidase & + & - & - & - & - & - & + & - & + & - \\
\hline Leucine arylamidase & - & + & + & + & + & + & + & + & + & + \\
\hline Myristate lipase & - & + & + & - & - & - & - & - & - & - \\
\hline Naphthol-AS-BI-phosphohydrolase & + & + & - & + & + & + & + & + & + & + \\
\hline Valine arylamidase & - & + & - & - & - & - & - & + & + & - \\
\hline \multicolumn{11}{|l|}{ Biochemical tests: } \\
\hline Aesculin & - & - & - & - & - & - & - & - & + & - \\
\hline Arbutin & - & - & - & - & - & - & - & + & + & - \\
\hline Nitrate reductase & - & + & - & + & + & - & - & - & + & + \\
\hline Urea hydrolysis & + & + & - & + & + & - & - & + & + & + \\
\hline \multicolumn{11}{|l|}{ Degradation of $(\%, w / v)$ : } \\
\hline Hypoxanthine $(0 \cdot 4)$ & - & - & - & - & + & - & - & + & + & - \\
\hline Tributyrin $(0 \cdot 1)$ & + & + & - & - & - & + & - & + & - & - \\
\hline Tween $80(0 \cdot 1)$ & + & + & - & - & + & + & - & - & - & + \\
\hline Tyrosine $(0 \cdot 5)$ & - & - & - & - & - & - & - & - & - & - \\
\hline Uric acid $(0 \cdot 5)$ & - & - & - & + & + & + & + & + & + & - \\
\hline Xanthine $(0 \cdot 4)$ & - & - & - & - & - & - & - & - & + & - \\
\hline
\end{tabular}

caprylate esterase, $\alpha$-glucosidase, $\beta$-glucosidase, naphtholAS-BI-phosphohydrolase and pyrazinamidase are produced, but myristate lipase, leucine arylamidase, valine arylamidase, cystine arylamidase, $\alpha$-chymotrypsin, $\alpha$-galactosidase, $\beta$ galactosidase, $\beta$-glucuronidase, $\alpha$-mannosidase, $\alpha$-fucosidase, $N$-acetyl- $\beta$-glucosaminidase, pyrrolidonylarylamidase and trypsin are not. Does not ferment D-glucose, glycogen, Dlactose, D-maltose, D-mannitol, D-ribose, sucrose or D-xylose. Utilizes $N$-acetyl-L-glutamic acid, D-alanine (weak), L-alanine, L-alanyl glycine (weak), L-alaninamide, $\alpha$-cyclodextrin, $\beta$ cyclodextrin, D-fructose 6-phosphate (weak), $\alpha$-D-glucose, L-glutamic acid, glycogen (weak), $\alpha$-hydroxybutyric acid, $\beta$-hydroxybutyric acid, $p$-hydroxyphenylacetic acid, $\alpha$ ketoglutaric acid, DL-lactic acid (weak), D-malic acid (weak), mannan, D-mannose, 3-methyl D-glucose (weak), D-psicose, L-pyroglutamic acid, pyruvic acid (weak), putrescine, Dsorbitol (weak), succinic acid (weak), sucrose (weak), Tweens 20 and 40 and uridine 5-monophosphate as sole carbon sources. Additional phenotypic properties are given in Table 1. Chemotaxonomic properties are typical of the genus Gordonia.
The type strain, CC-AB07 ${ }^{\mathrm{T}} \quad\left(=\mathrm{BCRC} \quad 16810^{\mathrm{T}}=\mathrm{DSM}\right.$ $44995^{\mathrm{T}}$ ), was isolated from a soil sample collected from the campus of National Chung Hsing University, Taichung, Taiwan.

\section{Acknowledgements}

We are grateful to Mr W. S. Huang for excellent technical assistance and to Dr Iain Sutcliffe (University of Northumbria, Newcastle upon Tyne, UK) for help with the fatty acid analyses. The study was supported by grants from the National Science Council and Ministry of Economic Affairs, Taiwan.

\section{References}

Brosius, J., Palmer, M. L., Kennedy, P. J. \& Noller, H. R. (1978). Complete nucleotide sequence of a $16 \mathrm{~S}$ ribosomal RNA gene from Escherichia coli. Proc Natl Acad Sci U S A 75, 4801-4805.

Felsenstein, J. (1981). Evolutionary trees from DNA sequences: a maximum-likelihood approach. J Mol Evol 17, 368-376.

Felsenstein, J. (1985). Confidence limits on phylogenies: an approach using the bootstrap. Evolution 39, 783-791. 
Felsenstein, J. (1989). PHYLIP - Phylogeny inference package (version 3.2). Cladistics 5, 164-166.

Fitch, W. M. (1971). Towards defining the course of evolution: maximum change for a specific tree topology. Syst Zool 20, 406-416.

Goodfellow, M. \& Maldonado, L. A. (2006). The families Dietziaceae, Gordoniaceae, Nocardiaceae and Tsukamurellaceae. In The Prokaryotes, vol. 3. Archaea, Bacteria, Firmacutes, Actinomycetes. Edited by F. Dworkin, S. Falkow, K. H. Schleifer \& E. Stackebrandt. New York: Springer (in press).

Gordon, R. E. (1967). The taxonomy of soil bacteria. In The Ecology of Soil Bacteria, pp. 293-321. Edited by T. R. G. Gray \& D. Parkinson. Liverpool: Liverpool University Press.

Gordon, R. E. \& Mihm, J. M. (1962). Identification of Nocardia caviae nov. comb. Ann N Y Acad Sci 98, 628-636.

lida, S., Taniguchi, H., Kageyama, A., Yazawa, K., Chibana, H., Murata, S., Nomura, F., Kroppenstedt, R. M. \& Mikami, Y. (2005). Gordonia otitidis sp. nov., isolated from a patient with external otitis. Int J Syst Evol Microbiol 55, 1871-1876.

Kim, S. B., Brown, R., Oldfield, C., Gilbert, S. C. \& Goodfellow, M. (1999). Gordonia desulfuricans sp. nov., a benzothiophenedesulphurizing actinomycete. Int J Syst Bacteriol 49, 1845-1851.

Kim, K. K., Lee, C. S., Kroppenstedt, R. M., Stackebrandt, E. \& Lee, S. T. (2003). Gordonia sihwensis sp. nov., a novel nitrate-reducing bacterium isolated from a wastewater-treatment bioreactor. Int J Syst Evol Microbiol 53, 1427-1433.

Kimura, M. (1980). A simple method for estimating evolutionary roles of base substitutions through comparative studies of nucleotide sequences. J Mol Evol 16, 111-120.

Kumar, S., Tamura, K., Jakobsen, I. B. \& Nei, M. (2001). MEGA2: molecular evolutionary genetics analysis software. Bioinformatics 17, $1244-1245$.

Kummer, C., Schumann, P. \& Stackebrandt, S. (1999). Gordonia alkanivorans sp. nov., isolated from tar-contaminated soil. Int J Syst Bacteriol 49, 1513-1522.

Lechevalier, M. P. \& Lechevalier, H. A. (1970). Chemical composition as a criterion in the classification of aerobic actinomycetes. Int J Syst Bacteriol 20, 434-443.
Lechevalier, M. P., De Bièvre, C. \& Lechevalier, H. A. (1977). Chemotaxonomy of aerobic actinomycetes: phospholipid composition. Biochem Syst Evol 5, 249-260.

Maldonado, L. A., Stainsby, F. M., Ward, A. C. \& Goodfellow, M. (2003). Gordonia sinesedis sp. nov., a novel soil isolate. Antonie van Leeuwenhoek 83, 75-80.

Saitou, N. \& Nei, M. (1987). The neighbor-joining method: a new method for constructing phylogenetic trees. Mol Biol Evol 4, 406-425.

Shen, F. T., Kämpfer, P., Young, C. C., Lai, W. A. \& Arun, A. B. (2005). Chryseobacterium taichungense sp. nov., isolated from contaminated soil. Int J Syst Evol Microbiol 55, 1301-1304.

Shen, F. T., Lu, H. L., Lin, J. L., Huang, W. S., Arun, A. B. \& Young, C. C. (2006). Phylogenetic analysis of members of the metabolically diverse genus Gordonia based on proteins encoding the gyrB gene. Res Microbiol 157, 367-375.

Soddell, J. A., Stainsby, F. M., Eales, K. L., Kroppenstedt, R. M., Seviour, R. J. \& Goodfellow, M. (2006a). Millisia brevis gen. nov., sp. nov., an actinomycete isolated from activated sludge foam. Int J Syst Evol Microbiol 56, 739-744.

Soddell, J. A., Stainsby, F. M., Eales, K. L., Seviour, R. J. \& Goodfellow, M. (2006b). Gordonia defluvii sp. nov., an actinomycete isolated from activated sludge foam. Int J Syst Evol Microbiol 56, 2265-2269.

Stackebrandt, E., Rainey, A. F. \& Ward-Rainey, N. L. (1997). Proposal for a new hierarchic classification system, Actinobacteria classis nov. Int J Syst Bacteriol 47, 479-491.

Takeuchi, M. \& Hatano, K. (1998). Gordonia rhizosphera sp. nov. isolated from the mangrove rhizosphere. Int J Syst Bacteriol 48, 907-912.

Thompson, J. D., Gibson, T. J., Plewniak, F., Jeanmougin, F. \& Higgins, D. G. (1997). The CLUSTAL_X windows interface: flexible strategies for multiple sequence alignment aided by quality analysis tools. Nucleic Acids Res 25, 4876-4882.

Wayne, L. G., Brenner, D. J., Colwell, R. R. \& 9 other authors (1987). Report of the ad hoc committee on reconciliation of approaches to bacterial systematics. Int J Syst Bacteriol 37, 463-464.

Xue, Y., Sun, X., Zhou, P., Liu, R., Liang, F. \& May, Y. (2003). Gordonia paraffinivorans sp. nov., a hydrocarbon-degrading actinomycete isolated from an oil-producing well. Int J Syst Evol Microbiol 53, 1643-1646. 